\title{
Strategies to reach and motivate migrant communities at high risk for TB to participate in a latent tuberculosis infection screening program: a community-engaged, mixed methods study among Eritreans
}

Ineke Spruijt ${ }^{1,2^{*}}$ D, Dawit Tesfay Haile ${ }^{2}$, Connie Erkens ${ }^{1}$, Susan van den Hof ${ }^{1,3}$, Simone Goosen ${ }^{4}$, Andrea ten Kate ${ }^{5}$, Hewan Teshome ${ }^{6}$, Marja Karels ${ }^{7}$, Marga Koenders ${ }^{8}$ and Jeanine Suurmond ${ }^{2}$

\begin{abstract}
Background: In the Netherlands, migrant populations with a high tuberculosis (TB) incidence are an important target group for TB prevention. However, there is a lack of insight in effective community-engaged strategies to reach and motivate these migrants to participate in latent TB infection (LTBI) screening and treatment programs.

Methods: In cocreation with Eritrean key figures and TB staff, we designed and executed six strategies to reach and motivate Eritrean communities to participate in LTBI programs, in five regions in the Netherlands. We registered participation in LTBI education and screening, and LTBI treatment uptake and completion. We used semi-structured group and individual interviews with Eritrean participants, key figures, and TB staff to identify facilitators and barriers.
\end{abstract}

Results: Uptake of LTBI education (13-75\%) and consequent screening (10-124\%) varied between strategies. LTBI screening uptake $>100 \%$ resulted from educated participants motivating others to participate in screening. Two strategies, using face-to-face promotion and targeting smaller groups, were the most successful. The program resulted in high LTBI treatment initiation and completion (both 97\%). Reported program barriers included: competing priorities in the target group, perceived good health, poor risk perception, and scepticism towards the program purpose. TB staff perceived the program as useful but demanding in terms of human resources.

Conclusions: Eritrean migrant communities can be successfully reached and motivated for LTBI screening and treatment programs, when sufficient (human) resources are in place and community members, well-connected to and trusted by the community, are engaged in the design and execution of the program.

Keywords: Tuberculosis, Latent tuberculosis infection, LTBI, Screening, Eritreans, Migrants, Community-engaged, Refugees

\footnotetext{
* Correspondence: ineke.spruijt@kncvtbc.org

${ }^{1}$ KNCV Tuberculosis Foundation, The Hague, The Netherlands

${ }^{2}$ Department of Public Health, Amsterdam Public Health Research Institute,

Amsterdam University Medical Centres, University of Amsterdam,

Amsterdam, The Netherlands

Full list of author information is available at the end of the article
}

(c) The Author(s). 2020 Open Access This article is licensed under a Creative Commons Attribution 4.0 International License, which permits use, sharing, adaptation, distribution and reproduction in any medium or format, as long as you give appropriate credit to the original author(s) and the source, provide a link to the Creative Commons licence, and indicate if changes were made. The images or other third party material in this article are included in the article's Creative Commons licence, unless indicated otherwise in a credit line to the material. If material is not included in the article's Creative Commons licence and your intended use is not permitted by statutory regulation or exceeds the permitted use, you will need to obtain permission directly from the copyright holder. To view a copy of this licence, visit http://creativecommons.org/licenses/by/4.0/ The Creative Commons Public Domain Dedication waiver (http://creativecommons.org/publicdomain/zero/1.0/) applies to the data made available in this article, unless otherwise stated in a credit line to the data. 


\section{Background}

In most low tuberculosis (TB) incidence countries, the majority (74\% in the Netherlands) of $\mathrm{TB}$ is foreign born [1] and $\mathrm{TB}$ rates in this group remain high for at least 5 to 10 years after arrival [2,3]. Therefore, to stimulate further decreases in $\mathrm{TB}$ incidence, prevention of TB through screening and treatment of latent TB infection (LTBI) among high-risk migrants is suggested as a strategy for low TB incidence countries $[4,5]$. In the Netherlands, LTBI screening and treatment among migrants at arrival is feasible $[6,7]$. Dutch TB policy advisors are therefore considering to replace current mandatory radiological TB entryscreening among migrants by LTBI screening and treatment [4]. However, this policy change does not target the large pool of persons with LTBI among settled migrants, who account for $60 \%$ of annual TB patients [8]. Therefore, one can argue that this group of settled, high-TB-risk migrants can also be considered as a target group for TB prevention.

Reaching and motivating migrant communities to participate in TB screening programs is not without difficulty. Barriers for screening uptake include low perceived susceptibility, stigmas and misconceptions about the disease; unfamiliarity with the concept of screening and preventive care; and limited attention to language barriers and cultural sensitivities [9-11]. To reach the population in question, engaging community members or community-based organizations, which are trusted by the community, can help overcome these barriers: they have access to the community; can channel information; educate and mobilize their community; and (hereby) alleviate stigma and promote the benefits of TB screening [5, 10, 12-16]. Therefore, designing a culturally-tailored LTBI education and screening program that engages the community and other stakeholders would be a promising way to offer LTBI screening and treatment to settled migrants [10, 17].

Since 2010, a high influx of Eritrean asylum seekers - mainly young adult men, literate but with low levels of education, and of Tigrinya ethnicity - have applied for and were granted asylum. Subsequently, many family members followed and entered the Netherlands through the family reunification program [13]. Despite a moderate estimated TB incidence rate of $89 / 100,000$ population in Eritrea [18], this cohort of Eritrean migrants have a high TB incidence in the Netherlands $[1,2]$. Therefore, they are a target population for TB prevention in the Netherlands. Although various interventions among migrant populations have been described in literature, we lack insight into which specific strategies - tailored to specific communities - will best promote the uptake of LTBI education, screening and treatment. Therefore, to reach and motivate Eritreans living in Dutch communities to participate in an LTBI education, screening and treatment program, we engaged local Eritrean key figures and TB care staff to identify and carry out tailored strategies.

\section{Methods}

\section{Aim, design and setting}

We used a community-engaged mixed-methods study design to develop and study strategies to reach Eritrean migrants, and motivate them to participate in an LTBI education, screening and treatment program. A community-engaged research approach involves community members who actively participate in generating ideas, contribute to decision-making, and share responsibility in the design and execution of a culturally appropriate program $[12,19]$.

Eritrean migrants with a maximum duration of stay in the Netherlands of 10 years were eligible for this study, as we expect this group to be at highest risk for TB compared to those who migrated more than 10 years ago [1, 2, 20]. We approached Public Health Services (PHS) which is responsible for TB care and prevention activities - with large Eritrean communities in their region (seven PHS out of 25), of whom five agreed to participate in this study.

\section{LTBI education screening and treatment program}

TB and LTBI screening and treatment activities were performed following the Dutch guidelines [21, 22], and consisted of three components: 1) TB and LTBI education, 2) LTBI screening and 3) LTBI treatment. The education and written materials were provided in Tigrinya, the Eritrean mother tongue. LTBI screening and treatment were offered free of charge. Additional file 1 gives a detailed overview of program procedures [see Additional file 1].

\section{TB and $L T B I$ education program}

Based on experiences of Eritreans described in previous studies [6,7], authors IS and DTH designed an education program on TB and LTBI. It consisted of a presentation, a short film [23], and interactive quizzes. DTH invited Eritreans from his social network to participate in 3 group discussions (respectively with $n=11, n=4$, $n=3$ ) in which we piloted and discussed the education program. Participants were mainly young adult men (only three females participated) and received a $€ 10$ voucher for their participation. According to the group discussions, we revised the education program and consequently gave a one-day training to seven Eritrean key figures (see below), hired by the project, to provide the 
education as part of the program. The LTBI education was organized on site.

\section{LTBI screening}

LTBI screening consisted of a health questionnaire, completed by participants, and QuantiFERON-TB Gold Plus (QFT-Plus; Qiagen, Germantown, MD) [22]. To allow participants to make an independent and informed decision on participation in the screening, the PHS organized the LTBI screening, on site or at the PHS, at least 2 days after the education session of the PHS.

\section{LTBI treatment}

The PHS invited all participants with a QFT-plus test result $\geq 0.35 \mathrm{IU} / \mathrm{ml}$ for consultation with the TB physician. TB physicians confirmed LTBI diagnosis after exclusion of TB disease and offered eligible participants a threemonth daily Isoniazid and Rifampicin combination treatment. TB nurses provided LTBI treatment support through regular contact based on the client's needs.

\section{Community engagement and strategies}

We engaged seven Eritrean community members - four adult females, one young adult man and two middle aged men - who spoke both Dutch and Tigrinya. They functioned as key figures in the development and execution of strategies to reach and motivate the Eritrean community. The key figures were, as such, already under contract with the PHS for other health-related projects. The key figures were active members of this study's PHS project teams, which further consisted of a TB nurse (who functioned as the PHS project coordinator), the primary researcher (IS), and additional PHS staff. In a first project team meeting, key figures explained the characteristics of the Eritrean community within the PHS region, such as age, male/female ratio, and community size. Additionally, the key figures identified places and gatherings where community members would regularly come together. Based on this information, the project team discussed strategies to reach and motivate the community members, including the number of people who could potentially be reached. Next, a plan of action was designed and discussed in a second project team meeting. Table 1 provides a detailed description of the strategies used by the PHSs.

\section{Quantitative data collection and analysis}

During the screening, all participants completed health questionnaires including additional information on level of education and household composition. For each person eligible for LTBI treatment, TB physicians completed questionnaires about language barriers, occurrence of side-effects, challenges experienced during the treatment and, if applicable, reason(s) for discontinuing LTBI treatment. We double entered data from questionnaires in MS-Access (Microsoft Corp, Seattle 206 WA, USA). Additionally, we collected data from the electronic TB client registration of the PHS and from the Netherlands TB register. Before analysis, all data was merged, validated, cleaned and completely anonymized. We calculated proportions for participants' characteristics and the cascade of care, including reasons for not initiating or completing LTBI treatment.

\section{Qualitative data collection and analyses}

We used semi-structured group interviews with the project teams $(n=4)$, and individual interviews $(n=10)$ plus group interviews $(n=5)$ with Eritrean participants, to evaluate strategies and identify LTBI screening and treatment program facilitators and barriers (Table 2). After familiarization with the data, we developed and refined schemes to guide the coding of transcripts from the interviews. In regular meetings authors DTH, IS and JS discussed coding, categories and interpretation of the data [24]. We used MAXQDA (Version 11, VERBI GmbH, Berlin, Germany) to assist in analyses of qualitative data. Additional file 2 provides the topic guides for the group and individual interviews [see Additional file 2].

\section{Results \\ Quantitative results}

We estimated to reach a total of 904 Eritrean migrants through all strategies employed in the five PHS settings. In total, 401 (44\%) persons attended LTBI education and 257 persons (64\% of attendees, $28 \%$ of number envisioned to reach) received LTBI screening. The uptake of LTBI education differed between strategies from 13\% (Strategy 3.3) to 75\% (Strategy 5) (Table 3). Invitations through mail and social media (strategy 1) and church meetings (strategy 6.1 and 6.2) were most promising in reaching large numbers of the target population. However, only strategy 6.1 succeeded in screening many persons $(n=70)$. Strategies 2.1, 2.2 (face-to-face), 4.3 (group housing) and 5 (sport club) were most successful and screened respectively 84,89 , and $50 \%$ of the envisioned target group. PHS staff encouraged individuals who participated in the education sessions of strategies 2.1, 2.2, and 4.3 to motivate and bring family and friends to the LTBI screening. This resulted in more individuals attending the LTBI screening than the education session (uptakes up to $124 \%$ of those educated).

Of 257 persons screened for LTBI, 30 (12\%) were diagnosed with LTBI (Fig. 1). Additional file 3 presents characteristics of the population screened and treated for LTBI [see Additional file 3]. Of those diagnosed with LTBI, 29 (97\%) participants started and 28 (97\%) completed LTBI treatment (Fig. 1). Seven (24\%) participants had reported side-effects (hepatotoxicity: $n=3$ ). 
Table 1 Strategies to reach and motivate Eritrean migrants living in Dutch communities

\begin{tabular}{ll}
\hline Strategies & Description of strategy \\
\hline $\begin{array}{l}\text { Strategy 1: Invitation through mail } \\
\text { and social media }\end{array}$ & The local community of PHS 1 lacked regular social gatherings, for example a church, which could be \\
& used as approaching strategy. Therefore, the PHS 1 project team approached the target group through \\
& individual invitation -consisting of a flyer in Tigrinya- by mail, for which addresses of the target group \\
& where obtained by the PHS through the municipality. Additionally, the key figure posted an invitation on \\
& a Facebook group for Eritreans in that city (approximately 120 members). \\
& LTBl education: organized twice, during a week night, at two different local community centres \\
& LTBI screening: approximately 1 week after education, on appointment, at the PHS \\
& One key figure of PHS 3 promoted the education session in a WhatsApp group of the church. (Additional \\
to strategy 2)
\end{tabular}

Strategy 2:Face-to-face promotion The key figure of PHS 1 asked other key figures -working for other PHS departments- to spread the invitation and promote participation within their network during face-to-face contacts. (Additional to strategy 1)

The project team of PHS 3 identified various places - Dutch language classes, libraries, the church, and the gym- where Eritreans regularly gather. At those places, key figures approached individuals to promote the upcoming education session verbally and by handing out flyers with invitations.

LTBI education: organized twice, during week night, at a local community centre

LTBI screening: organized three times, approximately 1 week after the education, during week day, at the PHS

Strategy 3: Dutch language classes PHS 1 and 2 used Dutch language classes (PHS 1 at one school, PHS 2 at two schools) to reach Eritrean migrants. The project team approached the school management to discuss the possibility to organize education sessions at the school. After agreement, a teacher (Strategy 3.1 - PHS 1) or the key figures (Strategy 3.2 - PHS 2) approached students to come to the education session and handed out flyers. One school handed out flyers and displayed posters in the school (Strategy 3.3 - PHS 2) to promote the education session.

LTBI education: organized three times, at two different schools

LTBI screening: approximately 1 week after the education session, once during week night at the PHS, twice on appointment during week day at the PHS

Strategy 4: Group housing

The key figures of PHS 2 (Strategy 4.1 and 4.2) and the TB nurse of PHS 4 (Strategy 4.3) utilized existing contacts with resident(s) of group housings. Group housings are temporary residents with up to 35 young adult females or males, who transferred from an asylum seeker centre and are waiting individual housing to come available. In consultation with the residents, the key figures organized an education session in a community space of the houses.

LTBI education: during a week night, at the house

LTBI screening: organized approximately 1 week after the education, during a week day at the house (strategy 4.3 (PHS 4)) or on appointment at the PHS (strategy 4.1 and 4.2 (PHS 2))

Strategy 5:Sports club

The TB nurse of PHS 2 approached an Eritrean soccer coach who organizes weekly soccer trainings for Eritrean migrants. In consultation with the coach, the TB nurse organized an education session after soccer training.

LTBI education: during a week night, after training at the sport club

LTBI screening: organized approximately 1 week after the education, during a week night, at the PHS

Strategy 6: Eritrean church

Strategy 6.1: One PHS4 key figure was a member of the church board of trustees and obtained their consent to promote the LTBI education and screening after a church service. Interested church members were asked to sign up for the screening. Registered members received an invitation by mail. Those who did not show-up for the first screening appointment were invited a second time.

Strategy 6.2: The key figure of PHS 4 brought the project researcher (IS) in contact with a priest of a church in the PHS 5 region. The priest allowed the team to promote the LTBI education and screening after a church service. After the promotion, church members were handed-out invitations with date and time of screening.

LTBI education: promotion of the intervention organized after the church service

LTBI screening: organized 1 week (PHS 4) / 2 weeks (PHS 5) after education session on appointment at the PHS

We arranged for church members who did not live in the PHS 4 or PHS 5 region to visit the PHS in their own region.

LTBI Latent tuberculosis infection, PHS Public Health Service, TB Tuberculosis

To overcome language barriers, professional interpreters translated during $13(45 \%)$ consultations, while Ethiopian/Eritrean TB nurses from the PHS translated during 14 (48\%) consultations. All clients received demand-driven LTBI treatment support. Additional file 4 shows results from LTBI treatment evaluation [see Additional file 4].

\section{Qualitative results}

Overall experience with the program

Overall, interview respondents appreciated the opportunity to be educated and tested for LTBI. They perceived the education as eye-opening and important, and hoped the program would continue to reach more Eritreans. Some respondents expressed their desire to 
Table 2 Qualitative research methods

\begin{tabular}{|c|c|}
\hline \multicolumn{2}{|c|}{ Group interviews with project teams $(n=4)^{\mathrm{a}}$} \\
\hline Participation & $\begin{array}{l}\text { The PHS project coordinator, the key figure(s), } \\
\text { additional PHS staff (such as the TB physician, TB } \\
\text { nurse, Medical Technical Assistant). }\end{array}$ \\
\hline Time & Approximately $1 \mathrm{~h}$ \\
\hline Location & At the PHS office \\
\hline Informed consent & A-priori audio-taped verbal consent \\
\hline Communication & Dutch \\
\hline Transcript & Verbatim in Dutch (by IS) \\
\hline Incentive & None \\
\hline \multicolumn{2}{|c|}{ Group interviews with Eritrean participants $(n=5)$} \\
\hline Participation & $\begin{array}{l}\text { Group interviews, each consisting of } 4 \text { to } 6 \\
\text { participants, took place immediately following the } \\
\text { LTBI screening }\end{array}$ \\
\hline Time & Between 30 and $45 \mathrm{~min}$ \\
\hline Location & At the PHS, in a separate room to ensure privacy \\
\hline $\begin{array}{l}\text { Informed } \\
\text { consent }\end{array}$ & Written a-priori informed consent \\
\hline Communication & Tigrinya \\
\hline Transcript & $\begin{array}{l}\text { Verbatim translated from Tigrinya in English (by } \\
\text { DTH) }\end{array}$ \\
\hline Incentive & None (beverages were provided) \\
\hline
\end{tabular}

Individual interviews with Eritrean participants diagnosed with LTBI $(n=10)$

$\begin{array}{ll}\text { Participation } & \begin{array}{l}\text { TB nurses asked Eritrean clients on LTBI treatment } \\ \text { for consent to be approached by phone for an } \\ \text { invitation to participate in an individual interview } \\ \text { and to set an appointment if willing to participate. }\end{array} \\ \text { Time } & \begin{array}{l}\text { Between } 15 \text { and } 30 \text { min } \\ \text { Location }\end{array} \\ \begin{array}{ll}\text { Informed } \\ \text { consent }\end{array} & \text { Wocation to the client's convenience } \\ \text { Communication a-priori informed consent } & \text { Tigrinya } \\ \text { Transcript } & \text { Verbatim translated from Tigrinya in English (by } \\ \text { Incentive } & \text { DTH) }\end{array}$

LTBI Latent tuberculosis infection, PHS Public Health Service, TB Tuberculosis ${ }^{a}$ One project team (PHS 5) was not interviewed because activities were organized, in consultation with the PHS 5 TB care staff, ad-hoc by the authors IS and DTH

be tested for other diseases, particularly HIV. Participants who received the LTBI treatment perceived the treatment support as important and respectful. Furthermore, respondents were thankful for the reimbursement of screening and treatment costs; some indicated they would not have been able to cover those costs themselves.

Eritrean respondent: "I think it is a huge support for us to get it for free! How would we have paid for this? I don't know if these medicines exist in our country? So, I consider myself lucky to get this opportunity." [Individual interview 1]

Overall, PHS staff perceived the program as relevant for this target population. However, they experienced the organization and execution of strategies as timeconsuming. All strategies required a flexible attitude from TB care staff to organize promotion activities - and some LTBI screenings - on location or outside office hours. Most PHS staff doubted feasibility to execute the activities in regular practice with current available resources. Furthermore, PHS staff questioned the effectiveness of the program because of low LTBI screening uptake.

\section{Program facilitators}

Between the different strategies, we identified the following overarching facilitators: 1) active, face-to-face outreach to the community, and 2) engagement of key figures. Furthermore, respondents suggested that repeating the information and screening opportunities would increase uptake of the program.

Eritrean respondent: "People keep saying they are healthy, but we all said the same thing. I never had any complaints; I was not coughing. Still it was sleeping in my body. Now we can prevent it from developing into the TB disease. Therefore, we should share our experience with those who didn't come, if you could organize a health education seminar again." [Individual interview 7]

Key figure 2: "They need time to really understand the purpose and importance. (... ) So, several announcements and several registration opportunities. After the first time, they will share their experience [with LTBI screening] among each other. Then organize a second time. Eventually, it will gain publicity and then they will cooperate." [Group interview PHS 4]

Active face-to-face outreach to the community Strategies that actively approached smaller groups in a faceto-face manner (Strategies 2, 4, 5) had highest uptake of LTBI education and screening. Key figures explained that face-to-face explanation is effective as it allows them to explain and emphasize the importance of the program, and immediately address misunderstandings or scepticism. Contrary strategies (strategies 1, 3.3 and 6.2) used written materials such as letters, flyers and posters. Respondents described those strategies as less effective because of the overload of information from different 
Table 3 Uptake of LTBI education and screening, ranked from most successful to least successful strategy

\begin{tabular}{|c|c|c|c|c|c|}
\hline \multirow[t]{2}{*}{$\overline{\mathrm{PHS}}$} & \multirow[t]{2}{*}{ Strategies } & \multirow{2}{*}{$\begin{array}{l}\text { Numbers envisioned to } \\
\text { reach } \\
\mathrm{n}\end{array}$} & \multirow{2}{*}{$\begin{array}{l}\text { Participated in LTBI } \\
\text { education } \\
\mathrm{n} \text { (\% of } \mathrm{n} \text { envisioned to } \\
\text { reach) }\end{array}$} & \multicolumn{2}{|l|}{$\begin{array}{l}\text { Received } \\
\text { LTBI screening }\end{array}$} \\
\hline & & & & $\begin{array}{l}\mathrm{n} \text { (\% of } \mathrm{n} \text { LTBI } \\
\text { education) }\end{array}$ & $\begin{array}{l}\text { (\% of } n \text { envisioned to } \\
\text { reach) }\end{array}$ \\
\hline \multicolumn{2}{|c|}{ Total } & 904 & 401 (44\%) & $257(64 \%)$ & $(28 \%)$ \\
\hline 4 & Strategy 4.3: Female group house & 35 & $25(71 \%)$ & $31(124 \%)^{a}$ & $(89 \%)$ \\
\hline \multirow[t]{2}{*}{3} & $\begin{array}{l}\text { Strategy 2.1: Face to face } \\
\text { promotion }\end{array}$ & 47 & $30(64 \%)$ & $62(124 \%)^{a}$ & $(84 \%)$ \\
\hline & $\begin{array}{l}\text { Strategy 2.2: Face to face } \\
\text { promotion }\end{array}$ & 27 & $20(74 \%)$ & & \\
\hline 2 & Strategy 5: Male football team & 20 & $15(75 \%)$ & $10(67 \%)$ & $(50 \%)$ \\
\hline 2 & Strategy 4.1: Female group house & 20 & $12(60 \%)$ & $9(75 \%)$ & $(45 \%)$ \\
\hline 4 & Strategy 6.1: Eritrean church & 200 & $65+(33 \%)^{b, c}$ & $70(108 \%)$ & $(35 \%)$ \\
\hline 2 & $\begin{array}{l}\text { Strategy 3.2: Dutch language } \\
\text { classes }\end{array}$ & 50 & $30(60 \%)$ & $16(53 \%)$ & $(32 \%)$ \\
\hline 1 & $\begin{array}{l}\text { Strategy 1: } \\
\text { Invitation through mail and social } \\
\text { media }\end{array}$ & 175 & $44(25 \%)$ & $32(73 \%)$ & $(18 \%)$ \\
\hline 1 & $\begin{array}{l}\text { Strategy 3.1: Dutch language } \\
\text { classes }\end{array}$ & 20 & $12(60 \%)$ & $3(25 \%)$ & $(15 \%)$ \\
\hline 2 & $\begin{array}{l}\text { Strategy 3.3: Dutch language } \\
\text { classes }\end{array}$ & 60 & $8(13 \%)$ & $7(88 \%)$ & $(12 \%)$ \\
\hline 2 & Strategy 4.2: Male group house & 50 & $30(60 \%)$ & $5(17 \%)$ & $(10 \%)$ \\
\hline 5 & Strategy 6.2: Eritrean church & 200 & $110(55 \%)^{d}$ & $11(10 \%)$ & $(6 \%)$ \\
\hline
\end{tabular}

PHS Public Health Service, LTBI Latent tuberculosis infection

aPersons who attended the education session were encouraged to motivate and bring friends and family to the LTBI screening, which resulted in LTBI screening uptake (compared to LTBI education uptake) percentages over $100 \%$

${ }^{b}$ Persons in the church who registered-after promotion talk after church service- to receive an invitation by mail for extensive education session and LTBI screening at the PHS

'One household member had to register to receive an invitation which was valid for the whole household

${ }^{d}$ Number of invitations handed out after the promotion talk after the church service

organizations that is sent to Eritreans who recently migrated (61\% of those screened for LTBI, migrated less than 3 years ago). Many Eritreans have difficulties understanding and prioritizing invitations. Consequently, they only take letters from the municipality into consideration, which can be recognized by their envelope and are known to contain compulsory appointments.

\section{Engagement of key figures and community members} Most PHS staff said that the key figures were crucial in approaching and reaching the target population. Key figures from PHS 3 were very well connected to the community: they were young, from the same generation of migrants, and thus their acquaintance already originated during the journey to the Netherlands. However, respondents from PHS 1 and 2 reported mistrust and lack of respect towards key figures. Eritrean key figures - often also functioning as interpreters - who migrated during the nineties are often perceived as supporters of the current Eritrean regime, from which the new generation of Eritrean migrants fled. Mistrust towards those key figures is further perpetuated by media and public discourse of incidents where Dutch immigration authorities have expelled interpreters because of their connection to the Eritrean government.

Key figure: "The young generation do not trust the key figures who have been in the Netherlands for 20 years. They [young generation] think that certain things happen to them personally because of the key figures, because they are the translators and are always around procedures such as housing." [Group interview PHS 1]

To overcome the issue of mistrust and to make future campaigns more appealing, some interview respondents suggested to engage Eritreans from the same generation who have participated in the program, for example through short promotion films.

\section{Progra1m barriers}

We identified the following overarching barriers: 1) competing priorities, 2) perceived good health and poor risk perception, and 3) scepticism about the project's purpose. Additional file 5 provides an overview of 


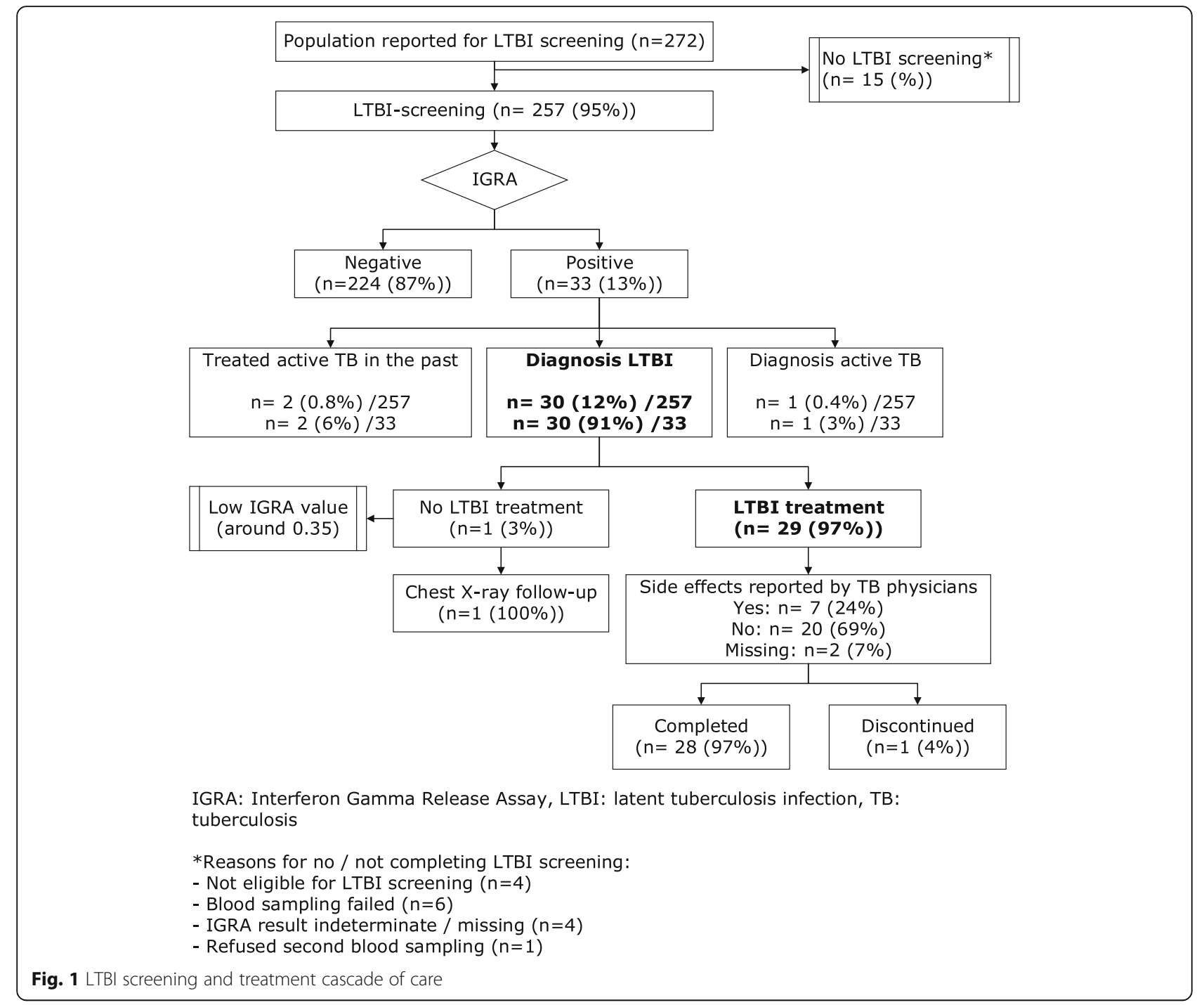

strategy specific facilitators, barriers and suggestions for future improvements [see Additional file 5].

Competing priorities of the target population Key figures said that it was sometimes difficult to motivate the target population to participate in the program because of competing priorities (Strategy 3.1 and 4.2). Some community members are occupied with pressing issues such as housing, family reunification, Dutch language school appointments and examinations, and employment, hence influencing participation in the program.

TB nurse: "The men said: I thought you guys came to tell us something about TB related to our housing condition. If not, why would I come? I don't care if I have TB, anything better than living in this house." [Group interview PHS 2]
Perceived good health and poor risk perception Some key figures said that at first the target population did not understand the relevance of attending the education about TB because they felt healthy, had a normal chest X-ray for TB at entry, and were unfamiliar with LTBI. Furthermore, the young age of some participants (Strategy 3.1 ) influenced the ability to relate the information to one's own health: despite the education they felt the disease would not affect them.

Eritrean respondent: "I participated only because I was at home. If I had a trip somewhere, I would not have come. I always thought I was healthy, and the education was not important. (... ) I only found out that I had LTBI because I did the blood test. So, I learned a lesson from my situation, and I try to explain it to others." [Individual interview 6] 
Stigma and scepticism about the project's purpose Some respondents felt stigmatized by the fact that the program targeted only Eritreans and not Arabic migrants. It made them feel like only Eritreans "brought $T B$ to the Netherlands". Furthermore, some respondents were sceptical about the project's purpose. They suspected the "real" project's goal was to test a new diagnostic test for TB. One key figure explained that this scepticism comes from gossip in the community about Western countries testing medical devices on African refugees, such as vaccines. Despite addressing these concerns, the scepticism may have resulted in negative peer pressure to participate in LTBI education and screening, especially in Strategy 6.2.

Eritrean participant: "They said this is a pilot project to do a blood test for TB. What do you say about the fact that they are testing it on us? They did not test it on the Arab people? What if the virus stays in the needle, they are using to test this new method and it infects us? It is normal to be sceptical about this." [Group interview 3]

\section{Discussion}

We engaged Eritrean key figures and TB care staff in developing and evaluating culturally appropriate strategies to reach and motivate Eritrean communities to participate in an LTBI screening and treatment program. Strategies in which key figures were well connected to the community, applied face-to-face promotion with individuals or small groups of community members, and in which participants brought friends and family to the LTBI screening were most successful in terms of LTBI education and uptake. After the education session, most participants perceived the LTBI screening as important and appreciated the opportunity to get educated, tested -and if necessary- treated, free-of-charge. Twelve percent of the screened population had LTBI. LTBI treatment initiation and completion proportions were very high (both 97\%).

In line with other study findings, we could reach the target group in places like churches, football clubs, language classes and community centres [10, 25, 26]. However, uptake of LTBI screening was suboptimal. Whereas Walker et al. showed great success, reaching LTBI screening uptake of 75\%, by using English language classes as outreach activities, targeting communities through Dutch language classes was one of the least successful strategies in our study [27]. In Walkers' project the ownership and shared responsibility among school management and staff -which was limited in our study- was likely key to their success. Furthermore, the LTBI screening uptake in our study is also low compared to the uptake of contact investigation (LTBI screening) among foreign-born individuals in the
Netherlands (77\%) [28]. The difference could be, partly, explained by the lack of intrinsic motivation among our target group: they are no recent (close) contacts of TB patients and therefore do not feel at high risk. Other barriers for program uptake were: other pressing priorities of participants, perceived stigma and scepticism towards the project, and perceived good health and misconceptions about TB susceptibility. These are in line with previous study findings $[9,11,29]$. The latter two barriers can be addressed through health and TB education, however, this may not address the challenge to motivate individuals to attend the education session.

To overcome barriers for uptake of the program, studies have identified the engagement of community members and stakeholders in the design and execution of the project as highly valuable $[5,10-15,25]$. Some of the key figures engaged in our study were from a different migrant generation and were mistrusted by the Eritrean participants in our study. This may have impeded the uptake of the program and shows that a culture sensitive approach includes attention for cultural, political and religious differences within populations and even communities.

We tend to measure the success of an LTBI education and screening program solely by LTBI screening uptake. However, LTBI treatment initiation and completion proportions in this program were higher than those observed among TB contacts in the Netherlands [28]. This shows that the culturally appropriate approach of the program is highly successful in motivating high risk Eritrean migrants to accept and complete LTBI treatment. Additionally, our study shows that encouragement of educated community members to motivate and bring family and friends to the LTBI screening can lead to additional participants attending the LTBI screening. Furthermore, creating awareness among community members through education could decrease stigma and potential future diagnostic delays [9] and improve uptake of future LTBI education and screening activities [10].

This study only targeted Eritreans because they currently have the highest $\mathrm{TB}$ incidence among migrants living in the Netherlands $[1,2]$. We are therefore limited in extrapolating study results to other migrant populations. However, considering the overlap of the study's identified barriers with those identified in previous literature, one might expect to find similar barriers when working with other migrant populations. We offered LTBI treatment free of charge, whereas normally the cost of medication is deducted from the obligatory deductible excess (385 euros) for health insurance in the Netherlands. We therefore do not know what effect out of pocket expenditure for treatment would have on LTBI treatment acceptance. Despite these limitations, this study is unique in its evaluation and comparison of multiple strategies to reach and motivate a target population 
for TB prevention programs. Our study therefore provides evidence-based information on the use of strategies which before were used more naturally and intuitively.

PHS staff considered the program as time demanding and requiring extended organizational flexibility. Given the unpredictable uptake of the screening, they doubted the feasibility and effectiveness of the program in daily practice. Yet, the organization of TB contact investigation requires similar flexibility and effort, and Dutch PHSs have proven to be very effective and ingenious in the execution of TB contact investigation [28, 30]. To further inform policy-makers on the implementation of future TB prevention strategies, we are currently modelling the cost-effectiveness of migrant LTBI screening programs and its impact on TB incidence and transmission. Program effectiveness and cost effectiveness could be increased by joining forces with other (infectious) disease screening programs with mutual target populations $[10,31]$. This collaboration could diminish stigma surrounding one or two particular disease(s) and meet the migrants' unmet health needs to be tested for other (infectious) diseases $[7,10]$.

\section{Conclusion}

Eritrean migrants eligible for TB prevention can be reached and motivated by engaging community members well connected and trusted by the community, using strategies which apply face-to-face promotion activities. Despite awareness-raising and culturally appropriate education, the uptake of the education session varied between PHSs and strategies and was often disappointing. Competing priorities and poor risk perception of the target population were among the main barriers for the uptake of the program. The educational program proved successful in most strategies in motivating the target population to participate in the LTBI screening and led to very high LTBI treatment initiation and completion rates among those with LTBI.

\section{Supplementary information}

Supplementary information accompanies this paper at https://doi.org/10. 1186/s12889-020-8390-9.

Additional file 1. Flowchart of LTBI screening and treatment process. Additional file 2. Interview topic guide, Topic guide for group interviews with Eritrean participants and project team members and TB care staff, and for individual interviews with Eritrean participants.

Additional file 3. Descriptive statistics of the study population.

Additional file 4. Evaluation of LTBI treatment by the TB physician.

Additional file 5. Strategy specific facilitators and barriers identified in interviews with TB care staff, Eritrean key figures and Eritrean participants.

\section{Abbreviations}

CXR: Chest X-ray; LTBI: Latent Tuberculosis Infection; PHS: Public Health Service; QFT-Plus: QuantiFERON-TB Gold Plus; TB: Tuberculosis

\section{Acknowledgements}

We would like to show our gratitude to all key figures -whose work was crucial in this study- for their eagerness to learn about TB and their energy with which they joined us in the fight against TB. We would like to thank all staff members from the department tuberculosis control of the Public Health Services, in particularly dr. Natasha van 't Boveneind-Vrubleuskaya, for their dedicated work in TB control and especially for their work with the LTBI screening and treatment which enabled this study.

\section{Authors' contributions}

IS wrote the study protocol in collaboration with DTH, CE, SvdH, SG, AtK, HT, MK1, MK2, and JS. Furthermore, IS supervised the design and execution of the strategies, performed data management and analyses and wrote the manuscript. DTH supervised the execution of the strategies, recruited Eritrean interview participants and performed and transcribed qualitative interviews among Eritrean participants. CE was daily supervisor of IS. JS supervised the qualitative research of this study. SvdH supervised the epidemiological component of this study. IS, DTH, CE, SvdH, SG, AtK, HT, MK1, MK2, and JS read, commented and approved the final manuscript.

\section{Funding}

This work was supported by the Netherlands Organization for Health Research and Development (ZonMw, grant number 50-53000-98-128). Qiagen provided the QuantiFERON-TB Gold Plus kits free of charge. The Netherlands Organization for Health Research and Development (ZonMw) nor Qiagen had any influence on the study design, the collection, analysis or interpretation of data or in writing the manuscript.

\section{Availability of data and materials}

The dataset generated and/or analysed during the current study are not publicly available due to the sensitivity of this study's data and the privacy of our participants, but are available from the Dutch Tuberculosis Data Registration Committee (Henrieke.schimmel@rivm.nl) on reasonable request.

\section{Ethics approval and consent to participate}

Research involving population health screening which is subjected to licensing as stated in the Population Screening Act (WBO) is not subjected to the Dutch Medical Research Involving Human Subjects Act (WMO) and thus does not need ethical approval (see https://english.ccmo.nl/ investigators/legal-framework-for-medical-scientific-research/laws/populationscreening-act). Screening for tuberculosis, including latent tuberculosis infection screening, is a population health screening for which the Public Health Services, who conduct the screening, are licensed under WBO. The Medical Ethical Committee (METC) of University Medical Centre Amsterdam (UMC-AMC) therefore waived the need for ethical approval of the study. Even though the need for ethical approval was waived, we followed the ethical principles of the Declaration of Helsinki, adopted by the World Medical Association (WMA Declaration of Helsinki 2000). All participants gave a-priori written informed consent for participating in the LTBI screening. Additionally, Eritrean interviewees gave written informed consent for participation in and audiotaping of the interviews. Project team members and TB care interviewees gave audiotaped verbal informed consent for participation in and audiotaping of the interviews, which was deemed sufficient because there are no Dutch guidelines for informed consent in interviews with professionals. We guaranteed the interviewee's anonymity by removing any personal identifiers from the data through designated coding.

\section{Consent for publication}

Not applicable.

\section{Competing interests}

The authors declare that they have no competing interests.

\section{Author details}

${ }^{1}$ KNCV Tuberculosis Foundation, The Hague, The Netherlands. ${ }^{2}$ Department of Public Health, Amsterdam Public Health Research Institute, Amsterdam University Medical Centres, University of Amsterdam, Amsterdam, The Netherlands. ${ }^{3}$ Present Address: National Institute for Public Health and the Environment (RIVM), Centre for Infectious Disease Control, Bilthoven, The Netherlands. ${ }^{4}$ Netherlands Association of Community Health Services, Utrecht, The Netherlands. ${ }^{5}$ Department of Tuberculosis Control, Public Health 
Service IJsselland, Zwolle, The Netherlands. ${ }^{6}$ Department of Tuberculosis Control, Public Health Service Haaglanden, Den Haag, The Netherlands. ${ }^{7}$ Department of Tuberculosis Control, Public Health Service Hollands Noorden, Alkmaar, The Netherlands. ${ }^{8}$ Department of Tuberculosis Control, Public Health Service Gelderland Zuid, Nijmegen, The Netherlands.

Received: 26 November 2019 Accepted: 21 February 2020

Published online: 12 March 2020

\section{References}

1. Slump E, Blijboom L, Bregman IM, Erkens CGM, van Hunen R, Schimmel HJ, et al. Tuberculose in Nederland 2017 [tuberculosis in the Netherlands 2017]. Surveillance report. Bilthoven: National Institute for Public Health and the Environment; 2018. [in Dutch].

2. van den Boogaard J, Slump E, Schimmel HJ, van der Hoek W, van den Hof S, de Vries G. High incidence of active tuberculosis in Eritrean and Somalian asylum seekers in the first five years after arrival in the Netherlands: time for a screening programme for latent infection. Bilthoven: (RIVM) NIfPHatE; 2018.

3. Vos AM, Meima A, Verver S, Looman CW, Bos V, Borgdorff MW, et al. High incidence of pulmonary tuberculosis persists a decade after immigration, The Netherlands. Emerg Infect Dis. 2004;10(4):736-9.

4. de Vries G, Riesmeijer R. National Tuberculosis Control Plan 2016-2020: Towards elimination Bilthoven: National Institute for Public Health and the Environment; 2016.

5. World Health Organization. The End TB strategy 2014. Available from: https://www.who.int/tb/strategy/en/.

6. Spruijt I, Erkens C, Suurmond J, Huisman E, Koenders M, Kouw P, et al. Implementation of latent tuberculosis infection screening and treatment among newly arriving immigrants in the Netherlands: a mixed methods pilot evaluation. PLoS One. 2019;14(7):e0219252.

7. Spruijt I, Tesfay Haile D, Suurmond J, van den Hof S, Koenders M, Kouw P, et al. Latent tuberculosis screening and treatment among asylum seekers: a mixed methods study. Eur Respir J. 2019;54(5).

8. Slump E, Bregman IM, Erkens CGM, Van Hunen R, Schimmel HJ, van Soolingen D, et al. Tuberculose in Nederland 2016 [Tuberculosis in the Netherlands 2016]. Surveillance report. Bilthoven: National Institute for Public Health and the Environment; 2016. [in Dutch].

9. de Vries SG, Cremers AL, Heuvelings CC, Greve PF, Visser BJ, Belard S, et al. Barriers and facilitators to the uptake of tuberculosis diagnostic and treatment services by hard-to-reach populations in countries of low and medium tuberculosis incidence: a systematic review of qualitative literature. Lancet Infect Dis. 2017;17(5):e128-e43.

10. Seedat F, Hargreaves S, Friedland JS. Engaging new migrants in infectious disease screening: a qualitative semi-structured interview study of UK migrant community health-care leads. PLoS One. 2014;9(10):e108261.

11. Wieland ML, Weis JA, Yawn BP, Sullivan SM, Millington KL, Smith CM, et al. Perceptions of tuberculosis among immigrants and refugees at an adult education center: a community-based participatory research approach. J Immigr Minor Health. 2012;14(1):14-22.

12. Blumenthal DS, DiClemente RJ, Braithwaite RL, Smith SA. Community-based participatory health research: issues, methods, and translation to practice. New York: Springer Publishing Company, LLC; 2013.

13. Ferrier J, Kahman M, Massink L. Handreiking voor ondersteuning van Eritrese nieuwkomers bij hun intergratie. Kennisplatform Integratie \& Samenleving; 2017.

14. Heuvelings CC, Greve PF, de Vries SG, Jelle Visser B, Belard S, Janssen S, et al. Effectiveness of service models and organisational structures supporting tuberculosis identification and management in hard-to-reach populations in countries of low and medium tuberculosis incidence: a systematic review. BMJ Open. 2018;8(9):e019642.

15. Sociaal en Cultureel Planbureau. Eritrese statushouders in Nederland. Den Haag: Sociaal en Cultureel Planbureau; 2018 [in Dutch].

16. Berrocal-Almanza LC, Botticello J, Piotrowski H, Karnani N, Kon OM, Lalvani A, et al. Engaging with civil society to improve access to LTBI screening for new migrants in England: a qualitative study. Int J Tuberc Lung Dis. 2019; 23(5):563-70.

17. Veldhuijzen IK, Wolter R, Rijckborst V, Mostert M, Voeten HA, Cheung Y, et al. Identification and treatment of chronic hepatitis B in Chinese migrants: results of a project offering on-site testing in Rotterdam, The Netherlands. J Hepatol. 2012;57(6):1171-6.
18. World Health Organization. Global Tuberculosis Report 2019. Geneva: World Health Organization; 2019. Licence: CC BY-NC-SA 3.0 IGO.

19. Health and Human Services Department. Centers for Disease Control and Prevention (U.S.). Principles of Community Engagement (Second Edition). Washington, DC: Centers for Disease Control and Prevention (CDC); 2011.

20. de Vries G, Gerritsen RF, van Burg JL, Erkens CG, van Hest NA, Schimmel HJ, et al. Tuberculosis among asylum-seekers in the Netherlands: a descriptive study among the two largest groups of asylum-seekers. Ned Tijdschr Geneeskd. 2016;160:D51.

21. Commision Practical Tuberculosis Control. Guideline: treatment of latent tuberculosis infection [in Dutch]. The Haque: KNCV Tuberculosefonds; 2015.

22. Control CPT. Guideline: interferon gamma release assay for the diagnosis of tuberculosis [in Dutch]. The Hague: KNCV Tuberculosis Foundation; 2010.

23. TB Alert. Tuberculosis: the real story [in Tigrinya] 2009. Available from: https://www.youtube.com/watch?v=89XaAFbaFwU.

24. Miles MB, Huberman M, Saldana J. Qualitative data analysis: a methods sourcebook: Arizona State University - Third edition; 2014.

25. Karels $\mathrm{M}$, Jansen-Aaldring $\mathrm{N}$. Community envolvement in raising awareness about tuberculosis among Somalian population. Int J Tuberc Lung Dis. 2014;18:115-6.

26. Usdin M, Dedicoat M, Gajraj R, Harrison P, Kaur H, Duffield K, et al. Latent tuberculous screening of recent migrants attending language classes: a cohort study and cost analysis. Int J Tuberc Lung Dis. 2017;21(2):175-80.

27. Walker CL, Duffield K, Kaur H, Dedicoat M, Gajraj R. Acceptability of latent tuberculosis testing of migrants in a college environment in England. Public Health. 2018;158:55-60.

28. van de Berg SEJ, van Rest JF, Erkens CGM, de Vries G. Evaluatie bron- en contactonderzoek bij tuberculosepatiënten in Nederland, 2011-2016 [in Dutch]. The Hague: KNCV Tuberculosis Foundation; 2019.

29. Badu E, Mpofu C, Farvid P. Towards TB Elimination in Aotearoa/New Zealand: Key Informant Insights on the Determinants of TB among African Migrants. Trop Med Infect Dis. 2018;3(2):44.

30. Mulder C, van Deutekom H, Huisman EM, Meijer-Veldman W, Erkens CG, van Rest J, et al. Coverage and yield of tuberculosis contact investigations in the Netherlands. Int J Tuberc Lung Dis. 2011;15(12):1630-7.

31. European Centre for Disease Prevention and Control. Public health guidance on screening and vaccination for infectious diseases in newly arrived migrants within the EU/EEA. Stockholm: ECDC; 2018.

\section{Publisher's Note}

Springer Nature remains neutral with regard to jurisdictional claims in published maps and institutional affiliations.

Ready to submit your research? Choose BMC and benefit from:

- fast, convenient online submission

- thorough peer review by experienced researchers in your field

- rapid publication on acceptance

- support for research data, including large and complex data types

- gold Open Access which fosters wider collaboration and increased citations

- maximum visibility for your research: over $100 \mathrm{M}$ website views per year

At $\mathrm{BMC}$, research is always in progress.

Learn more biomedcentral.com/submissions 